\title{
URBAN PLANNING OF SUSTAINABLE DEVELOPMENT MODEL FOR LIBYAN CITIES
}

| Received July 28 $8^{\text {th }}, 2021 \mid$ Accepted November 18 ${ }^{\text {th }}, 2021 \mid$ Available online December 15 $5^{\text {th }}, 2021$ DOI http://dx. doi. org/10.18860//ia.v6i4.13031 |

Ahmed A. Elgadi

Department of Civil Engineering,

Faculty of Engineering,

University of Azzaytuna, Tarhuna, Libya

Izudinshah Abd. Wahab*

Universiti Tun Hussein Onn Malaysia

Malaysia

izudinshah@gmail.com

\section{Lokman Hakim Ismai}

Architecture Department, Faculty of Civil

Engineering and Built Environment

Universiti Tun Hussein Onn Malaysia

Malaysia

\section{Fatma Abbas}

Architecture Department, Faculty of Civil Engineering and Built Environment

Universiti Tun Hussein Onn Malaysia Malaysia

\section{Emedya Murniwaty Samsudin}

Architecture Department, Faculty of Civil

Engineering and Built Environment

Universiti Tun Hussein Onn Malaysia

Malaysia

\begin{abstract}
The present sustainable metropolitan cities and the urban planning procedures in Libya are mainly aimed at reducing the impact on the environment due to the use of resources and improving life quality. Thus, the primary objective of this investigation is to create a model that focuses on reliable and valid urban planning of sustainable development, which highly reflects the Islamic way of live concerning the Libyan cities. The projected study model was tested experimentally using a review of 307 suitable samples, which included urban planning associated parties/industries, like the governmental institutions, academic research institutes, developer consultants, and planning and design engineers. Moreover, evaluations were done using the statistical software package Smart-PLS 2.0. The outcome shows that Libyan urban cities should comprise four major elements: social sustainability, environmental sustainability, economic sustainability, and institutional markers. The indicators for every element are studied in detail later in this investigation, which contributed significantly to gaining a better insight into the model for urban planning of sustainable development concerning the Libyan cities. The results provide useful insights for the urban planning industry in order to introduce the UPSD (Urban Planning of Sustainable Development] model, which is helpful as a strategy for Libyan organizations, urban planning contribution, and development to improve Libyan cities. Also, UPSD can be used to assess developed urban areas to analyze the quality of those areas and finally indicate the areas of enhancement.
\end{abstract}

\section{KEYWORDS: (CENTURY GOTHIC [7] CAPITAL BOLD)}

Sustainable urban cities; sustainable development indicators; urban planning

\section{INTRODUCTION}

According to 2011 figures, above $50 \%$ of the global population resides in urban areas. As a result, these urban residential areas are currently the primary places where more resources are consumed, impacting the environment. In 2009, these urban areas were responsible for final worldwide energy consumption of $62 \%$ and emitted $55 \%$ of the greenhouse gases in 2004 [1]. In developed countries, buildings cause $42 \%$ of global energy consumption and more than $50 \%$ of all materials extracted and emitted $35 \%$ of greenhouse gases [2]. Therefore, city planners must deal with an obvious requirement of developmental projects that need high sustainable development markers' performance from the private and public sectors. Nowadays, it is not very easy to realize sustainable cities in the region of the Middle East due to several obstacles and complexities faced when striving to attain sustainability goals [3]. In fact, in recent years, Libya has developed plans for achieving sustainability and allotted a high fraction of its funding to create and execute new urban areas in many Libyan provinces. Unfortunately, those new city areas face many issues while trying to attain the goals allotted to them. These cities do not contribute significantly to the development process since they do not appeal to the requisite population. Despite being closely related to the Islamic way of live, applying sustainable development concepts for areas with most Muslims is not easy. The primary problem of Libyan cities is not regarding the quantity but the life quality [4]. In the Middle Eastern and Libyan cities, sustainable development is erratic and unofficial within the boundaries of the cities.

The negligence in the study of city planning development in spite of the fact that city planning is a general issue in most Middle Eastern cities proves to be a major hindrance in attaining urban sustainability [5]. It indicates low levels of connectivity and diversity in urban regions and is related to various cities. Thus, this research directs attention towards developing a theoretical assessment-modeling prototype of indicators for urban cities while focusing on the role of city planning in realizing these realities. To handle the growing demand for sustainability examination and planning at a city level, this study developed a sustainable metropolitan cities assessment-modeling 
prototype, called the UPSD (Urban Planning Sustainable Development) model for Libyan cities, using the viewpoints from experts. The UPSD (Urban Planning of Sustainable Development) model is proposed by considering the functional practice of city design and planning. It is to be employed from the beginning of a project. Moreover, UPSD assessment is done using a set of indicators that represent the sustainability of the cities with respect to social, economic, and environmental sustainability as well as the institutional indicators. Also, UPSD not only serves as a strategy for developing sustainable cities, but can also be employed to evaluate the cities' quality by indicating which factors are not present and which factors are required to be improved.

\section{GENERAL SUSTAINABILITY DEVELOPMENT}

Sustainable development is viewed as the "development that meets the requirements of the present without compromising the ability of the future generation to meet their requests" [6]. The concept of sustainable development comes from the base points that encompass revolutionary ways to integrate the development of physical changes currently needed. Economic criteria and environmental, social, and institutional aspects require more consideration and attention [7]. Figure 1 demonstrates the relationships that link each category into effective compliance.

\section{- $\quad$ Environmental Sustainability}

As the most practiced effect on sustainable development evaluation tools, the environmental sustainability has been employed in the city planning process ever since the beginning of the 1970s [8]. This long-standing assessment tool includes a process of recognizing and predicting the potential effects of a proposed model on its environment. It is primarily applied to huge development schemes and, in the majority of the cases, is chiefly focused on the environmental aspects [9].

Since the environmental sustainability model has been employed in many countries around the world, there are certain slight changes in how it is utilized in various contexts. For example, the environmental sustainability is making a remarkable progress in the area of impact assessment by providing some indicators for being an interested party in the city planning process [10]. Nowadays, it is a legal basis in several countries, differentiating it from other impacts on sustainable development [11]. Nonetheless, environmental sustainability has its limitations that have led interested parties and planners to seek other corresponding forms of sustainable development.

Besides that, 12 indicators contribute to sustainable development in an environmental element based on judgment of selected experts. All the environmental indicators are shown in figure 2 . For this purpose, the following hypothesis is suggested:

H1.There is a positive relationship between environmental and urban planning of sustainable development for Libyan cities.

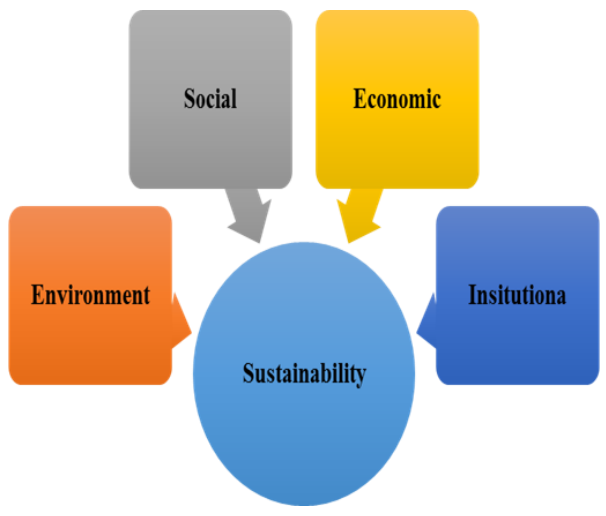

Figure 1: The four dimensions of sustainability

\section{- $\quad$ Social Sustainability}

Social sustainability is not the solitary new tool, which has developed from the environmental component and operates independently. As suggested by [12], there are two main causes for the development of new analysis tools using the environmental component as the main trunk: one of the reasons lies in the environmental concept open to various interpretations ranging from describing the environment as a biophysical unit to regarding it as an all-inclusive entity containing several other components; another reason is regarding the efforts of experts and interested parties belonging to different domains to bring about their issues into the limelight and modify the assessment tool for their advantage. Thus, social sustainability can be followed of its own accord or complement the process of environmental assessment [13].

The main objectives of a social sustainability procedure are to distinguish the effects of sustainable development on the population, suggest measures for diminishing the adverse effects, and create a medium for citizen involvement and social learning [13].

Hamdan et al. [14] claim that social sustainability has failed to acquire a powerful standing in political decision-making. It primarily acts as a report for the policymakers regarding the potential impacts of the model of sustainable development on different communal groups and contains advice on improvement measures. The ultimate decision on whether to endorse or reject the recommendation remains with the policymakers, who consider social sustainability as a tool to aid decision-making. It is also noteworthy that the same line of reasoning applies to other tools for assessment like the environmental element in several cases. Figure 2 consists of 11 effect indicators to the social element. For this purpose, the following hypothesis is proposed:

$\mathrm{H} 2$.There is a positive relationship between social and urban planning of sustainable development for Libyan cities.

\section{- $\quad$ Economic Sustainability}

During earlier decades, various models and policies were formed to endorse a creative economy to indicate the importance of financial balance and the steadiness of urban areas. One of these concepts is the 


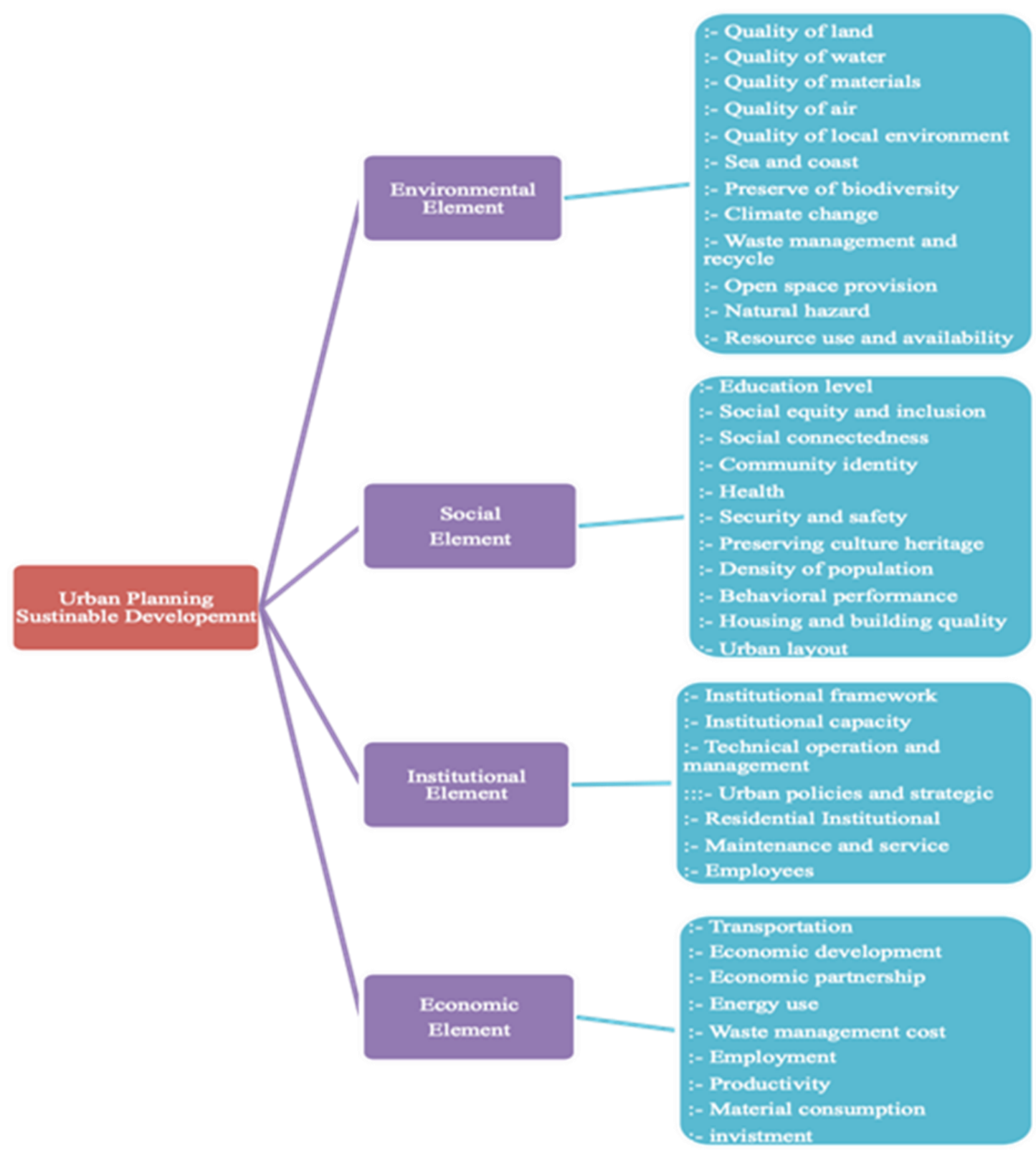

Figure 2: Sustainable development indicators modeling framework

development of a community and economy that supports and improves cultural motivations. Hence, the creative renewal of a city's economy is based on the development of socio-cultural infrastructures to attain financial benefits [15]. Figure 2 represents nine indicators of the proposed approach. Based on these studies, a hypothesis is formulated as follows:

$\mathrm{H} 3$. There is a positive relationship between economy and urban planning of sustainable development for Libyan cities.

\section{- Institutional Indicators}

The institutional indicators study hypothetical and conceptual rules of sustainable urban development highlighting the performance of futurology. The findings suggested that sustainable environment factors, socially sustainable situations, forms of economic sustainability, and city institution indicators have a significant role in the progress of the urban sustainable development concept, and reaching a sustainable urban neighborhood that relies on concurrent attention to all stated aspects [16]. Besides, increasing the stakeholders' and the city planners' awareness regarding developmental factors and execution of measures leading to city institution indicators and social balance facilitate sustainable urban development.

Maseland [17] attempted to present aspects, solutions, and indicators of excellent urban governance in the approach to futurology. In their view, once the regulatory organization is effective and 
efficient, it can employ the approach of futurology. Therefore, as presented in figure 2, the indicators are formed to reflect the effect of institutional indicators on sustainability. It has led to the following hypothesis. H4.There is a positive relationship between institutional and urban planning of sustainable development for Libyan cities.

- Modeling framework for urban planning of sustainable development indicators

To sum up, this study aims to recognize the indicators that contribute to the urban planning of sustainable development model for urban cities in Libya. Thus, it is necessary to examine the indicators of the urban planning of sustainable development model that have been acknowledged by past studies. The initial findings give an overview of the four components. It is believed to be an accurate classification of the wide range of eco-friendly urban planning development descriptions.

Table 1: Respondents' profile

\begin{tabular}{|c|c|}
\hline Profile & Percent \\
\hline \multicolumn{2}{|l|}{ Gender } \\
\hline Male & 61.8 \\
\hline Female & 38.2 \\
\hline \multicolumn{2}{|l|}{ Organization } \\
\hline Developer consultant & 27.5 \\
\hline Research academic institutes & 20.6 \\
\hline Designer and planning engineer & 19.6 \\
\hline Authority/government agency & 23.5 \\
\hline \multicolumn{2}{|l|}{ Category of organization } \\
\hline Government & 82.1 \\
\hline Private & 18.0 \\
\hline \multicolumn{2}{|l|}{ Experience } \\
\hline Below five years & 1.52 \\
\hline $5-10$ years & 22.10 \\
\hline $11-15$ years & 29.00 \\
\hline $16-20$ years & 14.72 \\
\hline 21-25 years & 19.00 \\
\hline $26-30$ years & 11.82 \\
\hline Above 30 years & 7.49 \\
\hline \multicolumn{2}{|l|}{ Education } \\
\hline Diploma & 5.73 \\
\hline Bachelor degree & 45.6 \\
\hline Master degree & 19.2 \\
\hline Doctor of Philosophy & 26.6 \\
\hline Certificates & 2.91 \\
\hline
\end{tabular}

\section{- Empirical analysis}

The structural (inner) and measurement (outer) models were combined to get a comprehensive structural equation model [18]. Model authentication was carried out using the Smart-PLS 2.0 software, a tool for structural equation modeling that uses a component-based style for estimation. This tool takes a 2-stage approach for data assessment. First, the measurement model was employed to assess and develop the validity and reliability (i.e., discriminant and convergent validity) of the instrument used for figure 3 research. Second, after the fine-tuning of indicators and the measurement model's approval, the structural model was assessed for the conceptualized relationships among the paradigms in the theoretical model.

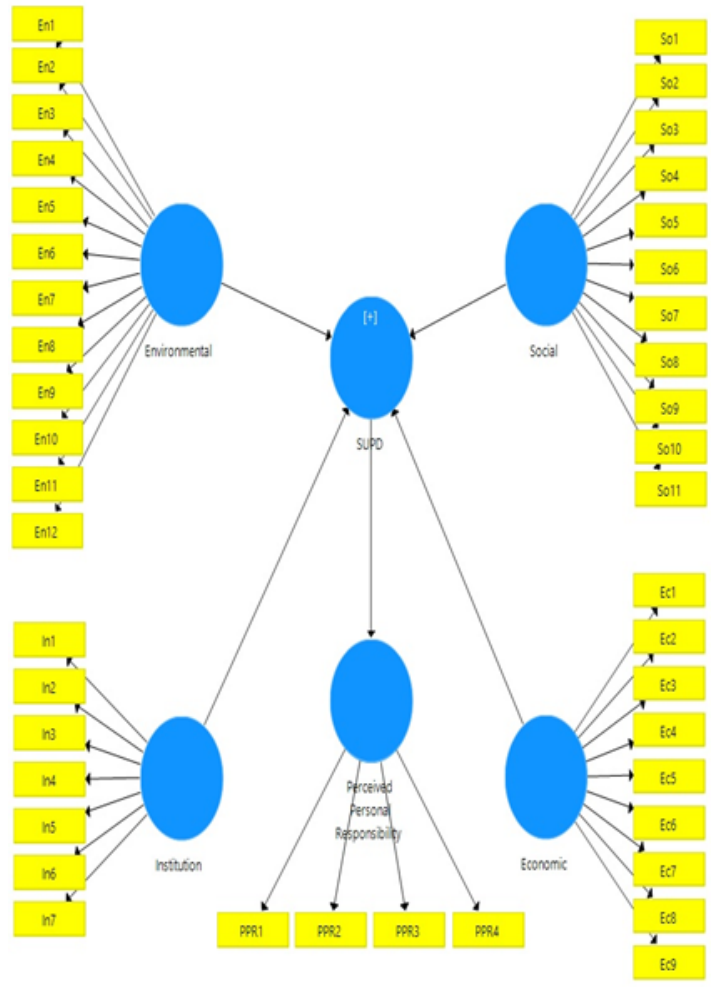

Figure 3: UPSD model run in Smart-PLS for the measurement model

\section{MEASUREMENT MODEL}

This part established convergent validity as well as reliability using the factor loadings. The scale items in this study were established with three average variances extracted $(A V E) \geq 0.5$, convergent validity $(C R) \geq 0.7$, and Cronbach's alpha $\geq 0.7$ [19]. The reliability and convergent validity of each construct are shown in Table 2.

Environmental element: All the indicators in this construct have factor loadings of more than 0.7 except for EN11 (natural hazard), which has a loading value of 0.471 which means that this construct also needs some modification. Other indicators have factor loadings ranging from 0.753 to 0.953 .

The $C R$ value for this construct is 0.810 , which is 
higher and greater than 0.5 .

Social element: The results of the social construct showed that $\mathrm{SO}_{3}$ (Social connectedness) and SO11 (Density of population), which have a loading value of 0.384 , and 0.582 , are lower than 0.6. Other indicators have factor loadings ranging from 0.703 to 0.939. Therefore, the $C R$ value for this construct is 0.782 , which is higher than the threshold value of 0.7 . However, its AVE value is 0.543 , which is still greater than the acceptable level. Hence, this construct should be considered for modification, and this will be further discussed in the section on iteration one analysis.

Economic element: As shown in Table 2, all the economic indicators have a high and significant loading on the corresponding construct. All exceed the recommended threshold value of 0.60 , ranging from 0.756 to 0.940 . In addition, the CR and AVE for this construct are 0.905 and 0.704 , respectively, both are higher than the threshold values.

Institutional element: The loading values of all indicators in this construct are higher than the required value of 0.7 , ranging from 0.728 to 0.930 . The $C R$ and AVE values for this construct are 0.888 and 0.665 , respectively, which are also higher than the threshold values.

Perceived Personal Responsibility: The PR (Perceived Responsibility) construct exceeds the requirements for indicator reliability with factor loading values ranging from 0.724 to 0.844 . Its convergent validity is also satisfactory, with $C R$ and AVE values of 0.872 and 0.578 , respectively.

As mentioned above, modifications to the model are needed. The analysis should include an examination of the composite reliability of all research constructs to ensure that they are above 0.70 [20]. After omitting the natural hazard, social connectedness, and density of population indicators related to environmental and social elements, the composite reliability of the environmental and social constructs increased from 0.810 to 0.891 and 0.782 to 0.972 , respectively. Table 2 shows that composite reliabilities of all indicators also exceeded the required minimum of 0.7. The AVE values of all constructs in the research model were examined. As presented in Table 3 , the AVE values for all constructs exceeded the threshold value of 0.50 [20]. Therefore, all three conditions for convergent validity were met.

Table 3: Construct composite, Cronbach's alpha, and AVE

\begin{tabular}{cccc}
\hline Construct & $\begin{array}{c}\text { Cronbach's } \\
\text { alpha }\end{array}$ & $\begin{array}{c}\text { Composite } \\
\text { Reliability }\end{array}$ & (AVE) \\
\hline Environmental & 0.911 & 0.891 & 0.674 \\
\hline Social & 0.921 & 0.972 & 0.661 \\
\hline Economic & 0.891 & 0.905 & 0.704 \\
\hline Institutional & 0.977 & 0.888 & 0.665 \\
\hline $\begin{array}{c}\text { Perceived Per- } \\
\text { sonal Responsi- } \\
\text { bility }\end{array}$ & 0.942 & 0.872 & 0.578 \\
\hline
\end{tabular}

\section{Discriminant validity}

Discriminant validity is defined as a measurement that ensures the uniqueness of every construct [21]. Discriminant validity shows to what degree the constructs used in a model are distinct from one another. Thus, all the constructs ought to be more associated with their unique measures compared to other constructs. A couple of measures of discriminant validity are generally suggested: criterion (for discriminant validity at construct level) [22].

The criterion suggested by Henseler et al. [22] was used, in which the AVE square root of each construct is evaluated against its bivariate associations with all differing constructs. Therefore, the AVE square root was examined to ensure that this quantity was above the associations among the constructs. The findings in table 4 demonstrate that for all the constructs, AVE quantities were greater than the construct's greatest squared relationship with any other dormant constructs. Therefore, the expert also considers sufficient discriminant validity when the constructs have AVE quantities higher than 0.5. Put differently, at least 50 percent of measurement variance is denoted by the construct.

Table 4: Discriminant validity of constructs

\begin{tabular}{cccccc}
\hline Construct & Ec & Evt & Ins & So & PPR \\
\hline Economic & 0.926 & & & & \\
\hline $\begin{array}{c}\text { Environ- } \\
\text { ment }\end{array}$ & 0.439 & 0.880 & & & \\
\hline $\begin{array}{c}\text { Institutio- } \\
\text { nal }\end{array}$ & 0.269 & 0.467 & 0.874 & & \\
\hline Social & 0.343 & 0.385 & 0.368 & 0.827 & \\
\hline PPR & 0.451 & 0.390 & 0.201 & 0.326 & 0.895
\end{tabular}

Subsequently, taking the findings of the above method jointly, there is strong evidence to support the discriminant validity of the constructs under study recommended in the model. Thus, according to per the construct validity and reliability, the measurement models are successfully authenticated.

\section{Assessment of the structural model}

In this portion, having inspected the outer model concerning validity and reliability, the researcher now evaluates the inner model that was carried out by employing the PLS technique, combined with resampling algorithms, namely bootstrapping. Key parameters to analyze the inner model are the determination coefficient (R2), estimated path coefficient $(\beta)$, and size of the effect (F2) [23].

\section{Coefficient of determination (R2)}

Examining the structural model lets the researcher to know how much variance in the dependent variable of interest can explain. In this research, one of the goals of this analysis was to examine the collective ability of the adoption elements (including EN, SO, EC, and IN) to explain the variances in (UPSD) urban planning of sustainable development and perceived (PR) personal responsibility towards adopting for cities in Libya. In 
Urban Planning of Sustainable Development Model For Libyan Cities

Table 2: Results of convergent validity

\begin{tabular}{|c|c|c|c|c|c|c|}
\hline Construct & Code & Indicators & $\begin{array}{c}\text { Factor } \\
\text { loadings }\end{array}$ & Alpha & C.R & AVE \\
\hline \multirow{12}{*}{ Environmental } & EN1 & Quality of land & 0.764 & \multirow{12}{*}{0.878} & \multirow{12}{*}{0.810} & \multirow{12}{*}{0.550} \\
\hline & EN2 & Quality of water & 0.821 & & & \\
\hline & $\mathrm{EN}_{3}$ & Quality of materials & 0.830 & & & \\
\hline & EN4 & Quality of air & 0.753 & & & \\
\hline & EN5 & Quality of local environment & 0.779 & & & \\
\hline & EN6 & Sea and coast & 0.811 & & & \\
\hline & EN7 & Preserve of biodiversity & 0.821 & & & \\
\hline & EN8 & Climate change & 0.953 & & & \\
\hline & EN9 & Waste recycling & 0.940 & & & \\
\hline & EN10 & Open space provision & 0.867 & & & \\
\hline & EN11 & Natural hazard & $\begin{array}{c}0.471 \\
\text { Omitted }\end{array}$ & & & \\
\hline & EN12 & Resource use and availability & 0.949 & & & \\
\hline \multirow{11}{*}{ Social } & $\mathrm{SO} 1$ & Education level & 0.783 ? & \multirow{11}{*}{0.743} & \multirow{11}{*}{0.782} & \multirow{11}{*}{0.543} \\
\hline & $\mathrm{SO}_{2}$ & Social equity and inclusion & 0.939 & & & \\
\hline & $\mathrm{SO}_{3}$ & Social connectedness & $\begin{array}{l}\text { ?0.384 } \\
\text { Omitted } \\
\end{array}$ & & & \\
\hline & $\mathrm{SO}_{4}$ & Community identity & $0.846 ?$ & & & \\
\hline & $\mathrm{SO}_{5}$ & Health & 0.937 & & & \\
\hline & SO6 & Security and safety & 0.704 ? & & & \\
\hline & $\mathrm{SO} 7$ & Behavioral performance & 0.813 & & & \\
\hline & SO8 & Housing and building quality & $0.703^{\text {? }}$ & & & \\
\hline & SO9 & Urban layout & 0.940 & & & \\
\hline & SO10 & Preserving culture heritage & 0.814 ? & & & \\
\hline & SO11 & Density of population & $\begin{array}{c}0.582 \\
\text { Omitted }\end{array}$ & & & \\
\hline \multirow{9}{*}{ Economic } & $\mathrm{EC} 1$ & Transportation & 0.820 & \multirow{9}{*}{0.891} & \multirow{9}{*}{0.905} & \multirow{9}{*}{0.704} \\
\hline & $\mathrm{EC} 2$ & Economic development & 0.811 & & & \\
\hline & $\mathrm{EC}_{3}$ & Economic Standard of Living & 0.872 & & & \\
\hline & $\mathrm{EC} 4$ & Energy use & 0.930 & & & \\
\hline & $\mathrm{EC} 5$ & Waste management cost & 0.910 & & & \\
\hline & EC6 & Employment & 0.768 & & & \\
\hline & EC7 & Productivity & 0.756 & & & \\
\hline & $\mathrm{EC} 8$ & Material consumption & 0.778 & & & \\
\hline & EC9 & Investment & 0.940 & & & \\
\hline \multirow{7}{*}{ Institutional } & IN1 & Institutional framework & 0.803 & \multirow{7}{*}{0.977} & \multirow{7}{*}{0.888} & \multirow{7}{*}{0.665} \\
\hline & $\mathrm{IN} 2$ & Institutional capacity & 0.728 & & & \\
\hline & $\mathrm{IN}_{3}$ & $\begin{array}{c}\text { Technical operation and } \\
\text { management }\end{array}$ & 0.930 & & & \\
\hline & IN4 & Urban policies and strategic & 0.732 & & & \\
\hline & IN5 & Residential Institutional & 0.929 & & & \\
\hline & IN6 & Maintenance and service & 0.831 & & & \\
\hline & IN7 & Employees & 0.892 & & & \\
\hline \multirow{4}{*}{$\begin{array}{l}\text { Perceived Personal } \\
\text { Responsibility }\end{array}$} & $\mathrm{PP}$ & PPR1 & 0.844 & \multirow{4}{*}{0.942} & \multirow{4}{*}{0.872} & \multirow{4}{*}{0.578} \\
\hline & PP & PPR2 & 0.762 & & & \\
\hline & PP & $\mathrm{PPR}_{3}$ & 0.724 & & & \\
\hline & PP & PPR4 & 0.788 & & & \\
\hline
\end{tabular}


PLS, this can be done by examining the R2 (variance accounted for) scores of the dependent variables of interest (UPSD and PR), as shown in Table 5.

Table 5. Variance accounted for $\mathrm{R} 2$ of dependent variables

\begin{tabular}{ccc}
\hline $\begin{array}{c}\text { Dependent } \\
\text { Variable }\end{array}$ & $\boldsymbol{R}^{2}$ & Level of Explanatory \\
\hline UPSD & 0.379 & Substantial \\
\hline PPR & 0.325 & Substantial \\
\hline
\end{tabular}

The first criterion examined was the coefficient of determination ( $\left.R_{2}\right)$ of endogenous latent variables. According to Henseler et al. [22]. Values of 0.02, 0.13, and 0.26 indicate weak, moderate, and substantial R2 values. The results showed that for the SUPD construct, R2 values (0.379) were above the substantial level of 0.26 . In other words, $39.0 \%$ of the variance in the SUPD model is explained by EN, SO, EC, and IN. The R2 value for the PR construct is also above the substantial level, explaining $35.6 \%$ of its variance. Overall, based on the coefficient of determination (R2) of the endogenous latent variables, it can be concluded that the model will provide a good prediction of future outcomes.

\section{Path coefficient $(\beta)$}

In PLS, every structural path or theory's significance (or insignificance) strength can be inspected. PLS computes a path coefficient, or a $\beta$ value (beta value), which specifies the path strength and the unique part of the independent parameter in describing the dependent parameter variance. Moreover, the statistical insignificance (or significance) of any paths or hypothesis can be inspected in PLS using bootstrapping analysis [24].

The findings showed that every path coefficient ranging from the central construct to the five hypothesized results was significant. Table 5 shows the path coefficients, $\beta$, and $t$-statistics. Besides determining which particular element makes the greatest unique contribution to predicting or explaining the variance in the dormant endogenous parameter, the values of $\beta$ were also determined. Table 6 catalogs the values of $\beta$ for every significant path and ranks the independent parameters (predictors) by the power of prediction ( $\beta$ ). The findings showed that PR (Perceived Responsibility) is best predicted by the UPSD model. On the contrary, the UPSD elements' best predictor is EN (environmental), then SO (social), then EC (economic), and finally IN (institutional).
Table 6: Results of path coefficients

\begin{tabular}{ccccc}
\hline Path & $\begin{array}{c}\text { Beta } \\
(\boldsymbol{\beta})\end{array}$ & $\begin{array}{c}\text { Standard } \\
\text { Error } \\
(\text { STERR) }\end{array}$ & $\begin{array}{c}\text { t- } \\
\text { value }\end{array}$ & Inference \\
\hline EN-> UPSD & 0.253 & 0.068 & 3.743 & Significant \\
\hline SO -> UPSD & 0.213 & 0.061 & 3.485 & Significant \\
\hline EC -> UPSD & 0.173 & 0.057 & 2.822 & Significant \\
\hline IN -> UPSD & 0.170 & 0.062 & 2.673 & Significant \\
\hline UPSD -> PR & 0.426 & 0.048 & 8.909 & Significant \\
\hline
\end{tabular}

\section{Effect size (F2)}

The last criterion for evaluating the PLS structural equation model required that the effect size of each path in the structural model be evaluated via Cohen's F2. The effect size measures whether the independent variable has a substantial influence on a dependent variable [23]. The following criteria were suggested by Ringle et al. [24] for interpreting the effect size: $0.02<\mathrm{F} 2 \leq 0.15$ for a small effect size, $0.15<$ F2 $\leq 0.35$ for a medium effect size, and F2 $>0.35$ for large effect size.

A review of the effect sizes of predictors exhibited further information regarding the individual contribution of each construct. For example, table 7 shows that (UPSD) Urban Planning Sustainable Development Model has a large effect on perceived personal responsibility. However, environmental on (SUPD), social on (UPSD), and economical on (UPSD), are presented because they have a medium effect size. Furthermore, institutional on (UPSD) was demonstrated to have a small effect size. As a result, the majority of the variance was accounted for by the combined effect of these constructs rather than by their separate, independent contributions.

Table 7: Result of effect size (F2)

\begin{tabular}{ccc}
\hline Path & Value & Effect \\
\hline Environmental -> (UPSD) & 0.247 & Medium \\
\hline Social $->$ (UPSD) & 0.284 & Medium \\
\hline Economic $->$ (UPSD) & 0.239 & Medium \\
\hline Institutional $->$ (UPSD) & 0.062 & Small \\
\hline (UPSD) $->$ (PR) & 0.466 & Large
\end{tabular}

\section{CONCLUSION}

The research set out to create a UPSD model for the Libyan cities has led to a requirement for a strategy for practitioners due to the absence of the 
understanding of the measures. The UPSD model was created as a fundamental idea for the urban planning of sustainable development. These components improve the performance in the planning of the cities and finally lead to their successful management. UPSD involves social, economic, environmental, institutional, and ethical concerns grouped as highly interrelated and inseparable components of the social life, that both of which influence and are influenced by social constructs. This study contributes to the conceptual knowledge by developing a valid and reliable scale to quantify urban planning of sustainable development model, which plays an important role for more comprehensive UPSD elements. The instrument's creation for research provides scales for measurement to implement the UPSD model that will ignite further interest and investigation in this field. Also, the absence of job description and responsibility among the practitioners of urban planning in Libya led an organized approach to assess and describe the UPSD model. Therefore, this study offers a scale for measurement to implement the UPSD model.

As the model remains a pretty underdeveloped area for research in the city planning literature, the creation provides primary insights in developing a UPSD modeling framework that would promote better evaluation practices. Concerning the practical consequence, there has been an increasing awareness of the requirement of UPSD evaluation systems in the last decade, as is apparent from the literature review. Thus, a substantiated model can be deployed by urban planning experts in Libya as an evaluation tool for assessing urban planning of sustainable development and estimating prospective impact, which will aid organizations and market players in making decisions. Besides, complete yet user-friendly and simple instruments will be helpful eventually in standardizing the UPSD assessment for both the voluntary and mandatory urban inspection schemes for better management of the cities. Moreover, the results of this research have boosted knowledge on the predictors of UPSD, and these results will be helpful to the communities, particularly the occupants, city planners, and governmental organizations in developing nations like Libya, to learn, disseminate, and incorporate a culture of UPSD built environment in the local population. Hence, this research plays a significant role in attaining the greatest quality standard, sustainable practices for development in the city-planning domain, as aimed by the Urban Planning Industry from 2006 to 2019 (urban agency planning Libya, 2018). The efforts for the model development include important factors for urban planning and management, which are design, function, and maintenance. So far, a performance-based urban model has not been designed in the Libyan context. The UPSD model is unique for Libya. In general, this model can contribute positively to the community through the improved urban planning industry. The model is supposed to be a valuable performance measure for UPSD and is also assumed to be a tool for creating an understanding of the relations between the various components that contribute to UPSD for cities.

\section{ACKNOWLEDGEMENT}

The authors would like to thank the Ministry of Higher Education (MOHE) and Universiti Tun Hussein Onn Malaysia, and Libyan- Urban Planning Agency. Fundamental Research Grant Scheme (FRGS), vot 1524, has supported this paper

\section{REFERENCES}

[1] A. A Elgadi, L.H. Ismail, "A review of sustainable neighborhood indicator for urban development in Libya", ARPN Journal of Engineering and Applied Sciences, vol. 11, no. 4, pp. 2606-2613, 2016.

[2] L.H. Ismail, M. Sibley, I. Abdul Wahab, \& A.A Elgadi, "Layout Design and Users' Perception of Different Types of High-Rise Office Buildings in Malaysia", Advanced Engineering Forum, Vol. 18, pp. 80-93, 2016, doi: https://doi.org/10.4028/ www.scientific.net/AEF.18.80

[3] A. Karban, Developing a framework for neighborhood-level urban sustainability assessment in Saudi Arabia, Diss. The University of Texas At San Antonio, 2014

[4] L. UPA, National Spatial Policy 2009-2030, Draft report, Tripoli: Urban Planning Agency, 2009

[5] E. Holden, K. Linnerud, \& D. Banister, "The imperatives of sustainable development", Sustainable Development, vol. 25, no. 3, pp. 213226, 2017, doi: https:// doi.org/10.4324/9780203022177

[6] G. H. Brundlant, Our Common Future, Report of the World Commission on Environment and Development, 2007.

[7] J. H. Spangenberg, "Institutional sustainability indicators: an analysis of the institutions in Agenda 21 and a draft set of indicators for monitoring their affectivity", Sustainable Development, vol. 10, no. 2, pp. 103-115, 2012, doi: https://doi.org/10.1002/sd.184.

[8] D.L., Johnson, S.H. Ambrose, T.J. Bassett, M.L. Bowen., D.E., Crummey, J.S. Isaacson, D.N. Johnson, P. Lamb, M. Saul, and N. A.E. Winter, "Meanings of Environmental Terms", Journal of Environmental Quality, 26, pp. 581-589, 2009.

[9] B. Ness, E. Urbel-Piirsalu, S. Anderberg \& L. Olsson, "Categorising tools for Sustainability Assessment", Ecological Economics, vol. 60, no. 3, pp. 498-508, 2007, doi: 10.1016/ j.ecolecon.2006.07.023 
[10] M. Lotteau, G. Yepez-Salmon, \& N. Salmon, "Environmental assessment of sustainable neighborhood projects through NEST, a decision support tool for early-stage urban planning", Procedia Engineering, vol. 115, pp. 6976, 2016. Doi: https://doi.org/10.1016/ j.proeng.2015.07.356

[11] A. A. Elgadi, L. H. Ismail, W. A. Al Bargi, \& A. S. Ali, "Selecting Indicators for The Sustainable Development of Residential Neighborhoods in Tripoli, Libya", in IOP Conference Series: Materials Science and Engineering, Vol. 160, No. 1, p. 012045, IOP Publishing, 2016,

[12] T. Hacking \& P. Guthrie, "A framework for clarifying the meaning of Triple Bottom-Line, Integrated, and Sustainability assessment", Environmental Impact Assessment Review, vol. 28, no. 2-3, pp. 73-89, 2009, doi: 10.1016/ j.ciar.2007.03.002.

[13] K. Murphy, (2012). The social pillar of sustainable development: a literature review and framework for policy analysis. Sustainability: Science, practice and policy, 8(1), 15-29.

[14] H. Hamdan, F. Yusof, \& M. A. Marzukhi, (2014). Social capital and quality of life in urban neighborhoods high-density housing. ProcediaSocial and Behavioral Sciences, 153, 169-179.

[15] H. Hesami, \& S. Shiva, "Identification of effective dimensions on forecasting urban planning with economic approach", Journal of Urban Economics and Management, vol. 4, no. 3, pp. 55-73, 2016.

[16] J. H. Spangenberg, S. Pfahl, \& K. Deller, "Towards indicators for institutional sustainability: lessons from an analysis of Agenda 21", Ecological Indicators, vol 2, no. 1-2, pp. 61-77, 2012, doi: https://doi.org/10.1016/ S1470-160X(02)00050-X
[17] R. Maseland, "Is colonialism history? The declining impact of colonial legacies on African institutional and economic development", Journal of Institutional Economics, vol. 14, no.2, pp. 259-287, 2018, doi: https://doi.org/10.1017/ S1744137417000315

[18] J. F. Hair, C. M. Ringle, \& M. Sarstedt, "PLSSEM: Indeed a Silver Bullet", The Journal of Marketing Theory and Practice, vol. 19, no.2, pp. 139-152, 2011, Doi: 10.2753/MTP10696679190202

[19] G. J. Geldhof, K. J. Preacher, \& M. J. Zyphur, "Reliability estimation in a multilevel confirmatory factor analysis framework", Psychological methods, vol. 19, no. 1, pp. 72-91, 2014, doi: https://doi.org/10.1037/a0032138.

[20] O. Gotz, K. Liehr-Gobbers, \& M. Krafft, Evaluation of Structural Equation Models Using the Partial Least Squares (PLS) Approach, Springer Handbooks of Computational Statistics, 2010

[21] G. Franke \& M. Sarstedt, "Heuristics Versus Statistics in Discriminant Validity Testing: A Comparison of Four Procedures", Internet Research, vol. 29, no. 3, pp. 430-447, 2019, doi: https://doi.org/10.1108/IntR-12-2017-0515

[22] J. Henseler, C. M. Ringle, \& M. Sarstedt, "A new criterion for assessing discriminant validity in variance-based structural equation modelling", Journal of the academy of marketing science, vol. 43, no. 1, pp. 115-135, 2015,

[23] N. Urbach, \& F. Ahlemann, "Structural equation modeling in information systems research using partial least squares", Journal of Information technology theory and application, vol. 11, no. 2, pp. 5-40, 2010,

[24] C. Ringle, D. Da Silva, \& D. Bido, Structural equation modeling with the Smart-PLS, Brazilian Journal of Marketing, vol. 13, no. 2, 2015 